\title{
Selective Crystal Growth and Structural, Optical, and Electronic Studies of $\mathrm{Mn}_{3} \mathrm{Ta}_{2} \mathrm{O}_{8}$
}

\author{
Karl Rickert, ${ }^{\dagger}$ Eric A. Pozzi, ${ }^{\dagger}$ Rabi Khanal, ${ }^{\ddagger}$ Masatoshi Onoue, ${ }^{\S} \|$ Giancarlo Trimarchi, ${ }^{\S}$ \\ Julia E. Medvedeva, ${ }^{\ddagger}$ Mark C. Hersam, ${ }^{\dagger, \perp}$ Richard P. Van Duyne, ${ }^{\dagger}$ and Kenneth R. Poeppelmeier*, ${ }^{\dagger}$ \\ ${ }^{\dagger}$ Department of Chemistry, ${ }^{\S}$ Department of Physics and Astronomy, and ${ }^{\perp}$ Department of Materials Science and Engineering, \\ Northwestern University, Evanston, Illinois 60208, United States \\ ${ }^{\ddagger}$ Department of Physics, Missouri University of Science \& Technology, Rolla, Missouri 65409, United States
}

\section{Supporting Information}

ABSTRACT: $\mathrm{Mn}_{3} \mathrm{Ta}_{2} \mathrm{O}_{8}$, a stable targeted material with an unusual and complex cation topology in the complicated $\mathrm{Mn}-\mathrm{Ta}-\mathrm{O}$ phase space, has been grown as a $\approx 3$-cm-long single crystal via the optical floating-zone technique. Single-crystal absorbance studies determine the band gap as $1.89 \mathrm{eV}$, which agrees with the value obtained from density functional theory electronic-bandstructure calculations. The valence band consists of the hybridized $\mathrm{Mn} \mathrm{d-O} \mathrm{p}$ states, whereas the bottom of the conduction band is formed by the Ta d states. Furthermore, out of the three crystallographically distinct $\mathrm{Mn}$ atoms that are four-, seven-, or eight-coordinate, only the former two contribute their states near the top of the valence band and hence govern the electronic transitions across the band gap.

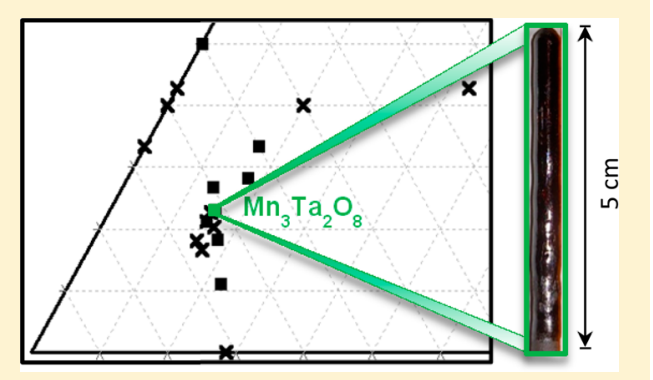

\section{INTRODUCTION}

Complex cationic topological networks (CCTNs), with multiple coordination sites for identical atomic species, have been investigated for important applications, including transparent electrodes and laser materials. Of particular interest are archetypal CCTNs that can accommodate a range of compositions and oxidation states while retaining the parent structure. ${ }^{1}$ Such networks offer the possibility of correlating desirable properties with dopants and substitutes because local alterations have far-reaching repercussions to the cation order in the crystalline lattice. As a result of the complexity that defines these materials, however, the structure solution of a CCTN is difficult without a single crystal. Furthermore, these complex systems are rife with secondary phases, and obtaining a pure polycrystalline phase presents its own challenges.

One example of a structure with such a complex network is the unusual and rare, anion-deficient, fluorite-related phase that is only exhibited, to the authors' knowledge, by $\mathrm{Ga}_{3-x} \mathrm{In}_{5+x^{-}}$ $\mathrm{Sn}_{2} \mathrm{O}_{16}$ (where $\left.0.3 \leq x \leq 1.6\right), \mathrm{Na}_{5} \mathrm{Ln}\left(\mathrm{WO}_{4}\right)_{4}$ (where $\mathrm{Ln}=\mathrm{Y}$, $\mathrm{La}, \mathrm{Ce}, \mathrm{Pr}, \mathrm{Nd}, \mathrm{Sm}, \mathrm{Eu}, \mathrm{Gd}, \mathrm{Tb}, \mathrm{Dy}, \mathrm{Ho}, \mathrm{Er}, \mathrm{Tm}, \mathrm{Yb}$, or Lu), and $\mathrm{Mn}_{3} \mathrm{Ta}_{2} \mathrm{O}_{8} \cdot{ }^{2-8}$ This CCTN maintains four distinct cation environments, four-, six-, seven-, and eight-coordinate, and a wide array of oxidation states, ranging from $1+$ to $6+$. In particular, $\mathrm{Mn}_{3} \mathrm{Ta}_{2} \mathrm{O}_{8}$ provides a challenge for single-crystal growth, owing to the similarities in the stoichiometry and the differences in the structure of the ternaries in the $\mathrm{Mn}-\mathrm{Ta}-\mathrm{O}$ phase space, as shown in Figure 1., ${ }^{5,9-21}$ Most of the known phases have only been characterized via powder X-ray diffraction (XRD), often in the presence of secondary phases, and vary widely in structure, including fluorite-related compositions such as $\mathrm{Mn}_{3} \mathrm{Ta}_{2} \mathrm{O}_{8}$, as well as the $\eta$-carbide, columbite, corundum, corundum/rock salt, CoSn, rutile, tantalite, trirutile, wodginite, and wolframite structure types. ${ }^{5,9,11,12,16}$ Single-crystal growth of ternaries in this system has been most successful in producing what are reported to be metastable structures, which are polymorphs of the reported stable structures of identical stoichiometry $\left(\mathrm{MnTa}_{2} \mathrm{O}_{6}\right.$, $\mathrm{Mn}_{4} \mathrm{Ta}_{2} \mathrm{O}_{9}$, and $\left.\mathrm{Mn}_{11} \mathrm{Ta}_{4} \mathrm{O}_{21}\right)$ obtained via solid-state syntheses. ${ }^{16}$ To date, only a single instance of a ternary manganese tantalate crystal that is classified as thermodynamically favored has been grown, to the authors' knowledge: the anion-deficient fluorite $\mathrm{Mn}_{0.55} \mathrm{Ta}_{0.45} \mathrm{O}_{1.7}{ }^{14}$ Thus far, the crystal growth methods reported for phases in the $\mathrm{Mn}-\mathrm{Ta}-\mathrm{O}$ system have been the arc-melt and oven-melt methods, and the limits of these methods have likely been reached. There are no reported single crystals of $\mathrm{Mn}_{3} \mathrm{Ta}_{2} \mathrm{O}_{8}$, but such crystals would be desirable for precise property characterization, such as determination of the optical band gap. ${ }^{22}$ Additionally, $\mathrm{Mn}_{3} \mathrm{Ta}_{2} \mathrm{O}_{8}$ combines a high density of six-coordinate sites, which appears to be related to good conductivity, with $\mathrm{Mn}^{2+}$ ions with $\mathrm{d}^{5}$ electronic configurations, which are appealing from a band-engineering point of view. ${ }^{23-26}$ Moving beyond p-block elements has already been accomplished in p-type materials, which can include $\mathrm{d}^{6}$ or $\mathrm{d}^{10}$ metals. ${ }^{27-29}$

The difficulty inherent in growing a single crystal of a targeted composition in the $\mathrm{Mn}-\mathrm{Ta}-\mathrm{O}$ phase space can be reduced by employing the optical floating-zone furnace method. This method maintains a smaller amount of molten sample than most other crystal growth procedures while

Received: April 15, 2015

Published: June 5, 2015 


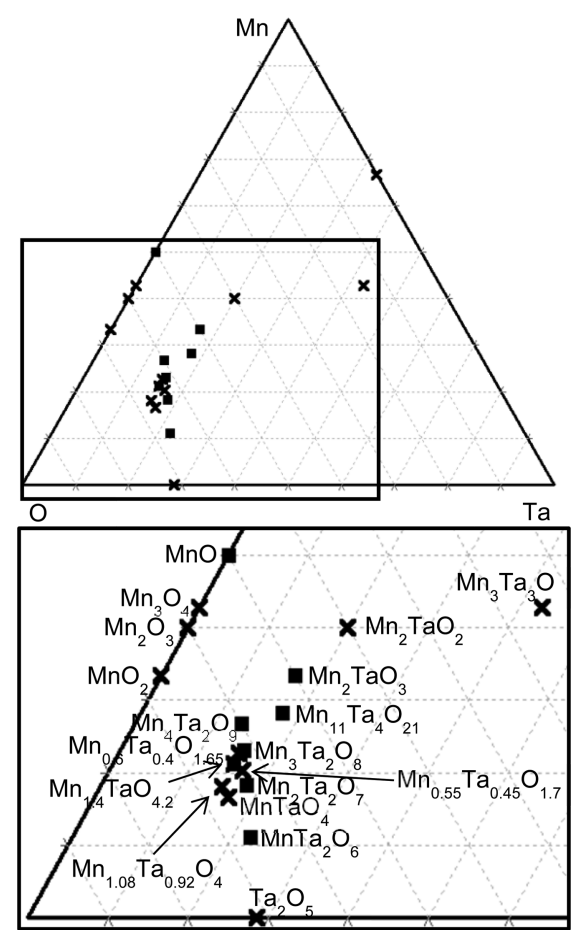

Figure 1. Phase diagram for the $\mathrm{Mn}-\mathrm{Ta}-\mathrm{O}$ system, showing the numerous stable phases of similar composition found in this system. Squares denote phases that contain manganese exclusively in the $2+$ state. Synthetic conditions, although similar, vary per composition.

feeding in material of the desired stoichiometry, which inhibits the formation of a heterogeneous molten zone by enabling precise control over the stoichiometry of the final crystal. Additionally, the oxidation state of manganese can be controlled by varying the atmosphere. Herein, the first growth of a large single crystal of $\mathrm{Mn}_{3} \mathrm{Ta}_{2} \mathrm{O}_{8}$ is reported along with the first measurements and computations of its electronic structure.

\section{EXPERIMENTAL AND THEORETICAL METHODS}

Crystal Growth. Feed material of manganese(II) oxide (Alfa Aesar, 99\%) and tantalum(V) oxide (Alfa Aesar, 99\%) with a 3:1 molar ratio $\left(3 \mathrm{MnO} / \mathrm{Ta}_{2} \mathrm{O}_{5}\right)$ was prepared via thorough mixing with a Fritsch planetary ball mill using agate media at $600 \mathrm{rpm}$ for 8 cycles of $15 \mathrm{~min}$, with pauses of $5 \mathrm{~min}$ between cycles. The feedstock was then packed into cylindrical molds of $6 \mathrm{~mm}$ diameter and $130 \mathrm{~mm}$ length, which were pressed at $60 \mathrm{MPa}$ for $5 \mathrm{~min}$. These rods were then removed from the mold and densified by firing in an argon atmosphere. The firing heated the samples to $1200{ }^{\circ} \mathrm{C}$ at a rate of $5{ }^{\circ} \mathrm{C} / \mathrm{min}$ and held the samples at $1200{ }^{\circ} \mathrm{C}$ for $28 \mathrm{~h}$. The resulting rods' densities were $\approx 6.5 \mathrm{~g} / \mathrm{cm}^{3}\left(\approx 92 \%\right.$ of the single-crystal density of $7.078 \mathrm{~g} / \mathrm{cm}^{3}$ determined in the structural characterization).

A feed rod was suspended from the upper shaft of a Crystal Systems Inc. FZ-T-10000-H-VI-VP optical image furnace with a platinum wire. A seed rod was firmly affixed to an alumina chuck with nickel wire, and the chuck was attached to the furnace's bottom shaft. Growth was carried out in the optical image furnace with four $300 \mathrm{~W}$ tungsten halide lamps. Each lamp was centered in an elliptical mirror, which focused the light onto the sample. The growth chamber was enclosed in a fused silica tube through which prepurified argon was flowed at $1.0 \mathrm{~L} / \mathrm{min}$ during the growth. $\mathrm{Mn}_{3} \mathrm{Ta}_{2} \mathrm{O}_{8}$ was grown at a rate of $3.00 \mathrm{~mm} / \mathrm{h}$ using $78.5 \%$ of the lamps' power, and the feed and seed rods had counterrotations of $13.0 \mathrm{rpm}$. The end result of this procedure was a 5 -cm-long deposition of reddish-brown solidified material on the seed rod. Of this, $\approx 3 \mathrm{~cm}$ was determined to be a single crystal based upon the lack of grain boundaries and its uniform a)

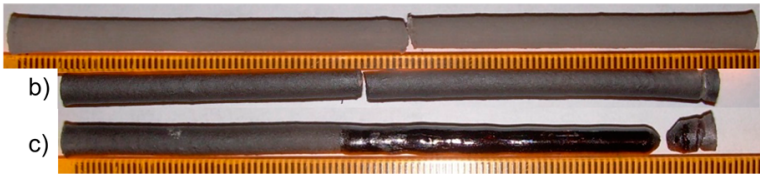

Figure 2. Seed (left) and feed (right) rods used in the crystal growth of $\mathrm{Mn}_{3} \mathrm{Ta}_{2} \mathrm{O}_{8}$ : (a) presintering; (b) postsintering; (c) postgrowth. Scale marks are millimeters. Approximately ${ }^{2} /{ }_{3}$ of the growth $(\approx 3 \mathrm{~cm})$ in part $\mathrm{c}$ is a single crystal. The remainder transitions from highly polycrystalline to single crystal along the direction of the growth.

Table 1. Crystallographic and Acquisition Parameters of the Single-Crystal X-ray Data for $\mathrm{Mn}_{3} \mathrm{Ta}_{2} \mathrm{O}_{8}$, Powder X-ray Data, and Powder Neutron Data

\begin{tabular}{|c|c|c|c|}
\hline & \multicolumn{3}{|c|}{$\mathrm{Mn}_{3} \mathrm{Ta}_{2} \mathrm{O}_{8}$} \\
\hline & single-crystal X-ray & $\begin{array}{c}\text { powder } \\
\text { X-ray }\end{array}$ & $\begin{array}{c}\text { powder } \\
\text { neutron }\end{array}$ \\
\hline $\mathrm{fw}(\mathrm{g} / \mathrm{mol})$ & 654.72 & 654.72 & 654.72 \\
\hline temperature $(\mathrm{K})$ & 100 & $\begin{array}{l}\text { room } \\
\text { temperature }\end{array}$ & $\begin{array}{l}\text { room } \\
\text { temperature }\end{array}$ \\
\hline$\lambda(\AA)$ & 0.71073 & 0.65 & 1.47 \\
\hline cryst syst & tetragonal & tetragonal & tetragonal \\
\hline space group & $I 4_{1} / a$ & $I 4_{1} / a$ & $I 4_{1} / a$ \\
\hline$a=b(\AA)$ & $11.2133(4)$ & $11.2782(2)$ & $11.2728(2)$ \\
\hline$c(\AA)$ & $9.7723(3)$ & $9.8030(3)$ & $9.8030(3)$ \\
\hline$\alpha=\beta=\gamma(\mathrm{deg})$ & 90 & 90 & 90 \\
\hline$V\left(\AA^{3}\right)$ & $1228.75(7)$ & 1246.92 & 1245.73 \\
\hline$Z$ & 8 & 8 & 8 \\
\hline$\rho_{\text {calc }}\left(\mathrm{g} / \mathrm{cm}^{3}\right)$ & 7.078 & 6.98 & 6.98 \\
\hline$\mu\left(\mathrm{mm}^{-1}\right)$ & 41.486 & & \\
\hline$F(000)$ & 2280.0 & & \\
\hline cryst size $\left(\mathrm{mm}^{3}\right)$ & $\begin{array}{l}0.247 \times 0.304 \\
\times 0.413\end{array}$ & & \\
\hline $\begin{array}{l}\theta \text { range for data } \\
\text { collection (deg) }\end{array}$ & $2.76-30.04$ & $8.5-14.5$ & \\
\hline index ranges & $-15 \leq h \leq 15$ & & \\
\hline & $-15 \leq k \leq 15$ & & \\
\hline & $-13 \leq l \leq 13$ & & \\
\hline reflns collected & 7530 & 1190 & 1943 \\
\hline indep reflns & $904\left(R_{\mathrm{int}}=0.1293\right)$ & & \\
\hline $\begin{array}{l}\text { completeness to } \\
\theta=30.04(\%)\end{array}$ & 100 & & \\
\hline refinement method & $\begin{array}{l}\text { full-matrix least } \\
\text { squares on } F^{2}\end{array}$ & Rietveld & Rietveld \\
\hline $\begin{array}{l}\text { data/restraints/ } \\
\text { parameters }\end{array}$ & $904 / 0 / 60$ & $1190 / 0 / 74$ & $1943 / 0 / 58$ \\
\hline GOF & 1.300 & & \\
\hline $\begin{array}{l}\text { final } R \text { indices } \\
{[I>4 \sigma(I)]^{a}}\end{array}$ & $\begin{array}{l}R_{\mathrm{obs}}=0.0421, w R_{\mathrm{obs}} \\
\quad=0.1133\end{array}$ & & \\
\hline$R$ indices (all data) & $\begin{array}{l}R_{\mathrm{all}}=0.0421, w R_{\mathrm{all}}= \\
\quad 0.1133\end{array}$ & $R_{\mathrm{F}}=0.063$ & $R_{\mathrm{F}}=0.006$ \\
\hline extinction coefficient ${ }^{b}$ & $0.0080(5)$ & & \\
\hline $\begin{array}{l}\text { largest diff peak and } \\
\text { hole }\left(\mathrm{e} / \AA^{3}\right)\end{array}$ & 6.74 and -2.27 & & \\
\hline reported $T_{\min }, T_{\max }$ & $0.004,0.035$ & & \\
\hline $\begin{array}{l}{ }^{a} R=\sum\left\|F_{o}|-| F_{c}\right\| \div \\
\text { and calcd } w\left(F_{o}\right)=[\sigma \\
\left.+2 F_{c}^{2}\right) / 3 . b_{\text {The extin }} \\
\text { the X-ray wavelength } \\
\text { the optical studies } m\end{array}$ & $\begin{array}{l}\sum\left|F_{\mathrm{o}}\right| ; w R=\left\{\sum[w(\mid\right. \\
{ }^{2}\left(F_{\mathrm{o}}^{2}\right)+(0.0486 P)^{2} \\
\text { ction coefficient men } \\
\text { used for structure } \mathrm{s} \\
\text { entioned later. }\end{array}$ & $\begin{array}{l}\left.\left|F_{\mathrm{o}}\right|^{2}-\left|F_{\mathrm{c}}\right|^{2}\right)^{2} / \\
+40.33 P]^{-1}, \mathrm{n} \\
\text { tioned here is } \\
\text { olution and is }\end{array}$ & $\begin{array}{l}\left.\left.\sum w\left(\mid F_{\mathrm{o}}{ }^{4}\right)\right]\right\}^{1 / 2} \\
\text { here } P=\left(F_{\mathrm{o}}{ }^{2}\right. \\
\text { with regard to } \\
\text { separate from }\end{array}$ \\
\hline
\end{tabular}

extinguishment of polarized light. The rods are pictured in Figure 2 at each stage of this procedure.

Structural Characterization. A portion of the single-crystal section was removed via cleavage. This portion was then carefully 
Table 2. Selected Interatomic Distances (̊) and Bond Angles (deg) for $\mathrm{Mn}_{3} \mathrm{Ta}_{2} \mathrm{O}_{8}$

\begin{tabular}{|c|c|c|c|c|c|}
\hline $\mathrm{Ta}-\mathrm{O} 1$ & $1.892(7)$ & $\mathrm{Mn} 1-\mathrm{O} 3$ & $2.000(6)$ & $\mathrm{Mn} 2-\mathrm{O} 1(4 \times)$ & $2.236(6)$ \\
\hline $\mathrm{Ta}-\mathrm{O} 4$ & $1.919(6)$ & $\mathrm{Mn} 1-\mathrm{O} 3$ & $2.052(6)$ & $\mathrm{Mn} 2-\mathrm{O} 3(4 \times)$ & $2.620(6)$ \\
\hline $\mathrm{Ta}-\mathrm{O} 3$ & $1.926(6)$ & $\mathrm{Mn} 1-\mathrm{O} 1$ & $2.145(6)$ & & \\
\hline $\mathrm{Ta}-\mathrm{O} 2$ & $2.009(7)$ & $\mathrm{Mn} 1-\mathrm{O} 1$ & $2.455(6)$ & $\mathrm{Mn} 3-\mathrm{O} 2(4 \times)$ & $1.994(6)$ \\
\hline $\mathrm{Ta}-\mathrm{O} 4$ & $2.034(6)$ & $\mathrm{Mn} 1-\mathrm{O} 4$ & $2.488(6)$ & & \\
\hline \multirow[t]{2}{*}{$\mathrm{Ta}-\mathrm{O} 2$} & $2.136(6)$ & $\mathrm{Mn} 1-\mathrm{O} 2$ & $2.516(7)$ & & \\
\hline & & $\mathrm{Mn} 1-\mathrm{O} 4$ & $2.625(6)$ & & \\
\hline $\mathrm{Mn} 1-\mathrm{O} 1-\mathrm{Mn} 1$ & $97.8(2)$ & $\mathrm{Mn} 1-\mathrm{O} 1-\mathrm{Mn} 2$ & $100.7(2)$ & $\mathrm{Mn} 1-\mathrm{O} 2-\mathrm{Mn} 3$ & $113.8(3)$ \\
\hline $\mathrm{Mn} 1-\mathrm{O} 3-\mathrm{Mn} 1$ & 108.1(3) & & $102.4(3)$ & & \\
\hline
\end{tabular}

Table 3. Atomic Coordinates and Equivalent Isotropic Displacement Parameters for $\mathrm{Mn}_{3} \mathrm{Ta}_{2} \mathrm{O}_{8}$ from Single-Crystal XRD, Powder ND, and Synchrotron Powder XRD ${ }^{a}$

\begin{tabular}{|c|c|c|c|c|c|}
\hline atom (coord. \#) & site & $x$ & $y$ & $z$ & $U_{\text {eq }}\left(\AA^{2}\right)$ \\
\hline \multirow[t]{3}{*}{ Ta1 (6) } & $16 \mathrm{f}$ & $0.07762(4)$ & $0.55617(3)$ & $0.12974(3)$ & $0.0083(3)^{b}$ \\
\hline & & $0.07821(7)$ & $0.55600(7)$ & $0.1299(1)$ & $0.0021^{c}$ \\
\hline & & $0.07743(7)$ & $0.55661(9)$ & $0.1300(1)$ & $0.00641(2)^{d}$ \\
\hline \multirow[t]{3}{*}{ Mn1 (7) } & $16 f$ & $-0.2021(1)$ & $0.6294(1)$ & $0.1531(2)$ & $0.0128(3)^{b}$ \\
\hline & & $-0.2012(2)$ & $0.6294(2)$ & $0.1510(2)$ & $0.0126^{c}$ \\
\hline & & $-0.1995(3)$ & $0.6280(5)$ & $0.1551(3)$ & $0.0077(1)^{d}$ \\
\hline \multirow[t]{3}{*}{ Mn2 (8) } & $4 \mathrm{~b}$ & 0 & 0.75 & 0.375 & $0.01145(6)^{b}$ \\
\hline & & 0 & 0.75 & 0.375 & $0.0135^{c}$ \\
\hline & & 0 & 0.75 & 0.375 & $0.0073(2)^{d}$ \\
\hline \multirow[t]{3}{*}{ Mn3 (4) } & $4 a$ & 0 & 0.75 & -0.125 & $0.0098(6)^{b}$ \\
\hline & & 0 & 0.75 & -0.125 & $0.0051^{c}$ \\
\hline & & 0 & 0.75 & -0.125 & $0.0071(2)^{d}$ \\
\hline \multirow[t]{3}{*}{$\mathrm{O} 1$} & $16 \mathrm{f}$ & $0.1290(5)$ & $0.7009(6)$ & $0.2098(6)$ & $0.010(1)^{b}$ \\
\hline & & $0.1282(1)$ & $0.7016(1)$ & $0.2101(1)$ & $0.0078^{c}$ \\
\hline & & $0.138(1)$ & $0.698(1)$ & $0.221(1)$ & $0.0043(3)^{d}$ \\
\hline \multirow[t]{3}{*}{$\mathrm{O} 2$} & $16 f$ & $-0.0371(6)$ & $0.6029(5)$ & $-0.0187(7)$ & $0.011(1)^{b}$ \\
\hline & & $-0.0367(1)$ & $0.6035(1)$ & $-0.0187(1)$ & $0.0053^{c}$ \\
\hline & & $-0.040(1)$ & $0.607(1)$ & $-0.013(1)$ & $0.0043(2)^{d}$ \\
\hline \multirow[t]{3}{*}{$\mathrm{O} 3$} & $16 f$ & $-0.0589(5)$ & $0.5522(6)$ & $0.2493(6)$ & $0.011(1)^{b}$ \\
\hline & & $-0.0527(1)$ & $0.5580(1)$ & $0.2496(1)$ & $0.0075^{c}$ \\
\hline & & $-0.054(1)$ & $0.562(1)$ & $0.247(1)$ & $0.0056(3)^{d}$ \\
\hline \multirow[t]{3}{*}{$\mathrm{O} 4$} & $16 f$ & $0.1828(5)$ & $0.4632(5)$ & $0.2421(6)$ & $0.010(1)^{b}$ \\
\hline & & $0.1832(1)$ & $0.4626(1)$ & $0.2423(1)$ & $0.0078^{c}$ \\
\hline & & $0.190(1)$ & $0.461(1)$ & $0.243(1)$ & $0.0048(2)^{d}$ \\
\hline
\end{tabular}

${ }^{a_{T}}$ The coordinates for footnotes $\mathrm{c}$ and $\mathrm{d}$ were reported with an alternate origin and positions in the asymmetric unit. For comparison purposes, the reported values were transformed to the standard form described by Sheldrick to yield the above values. ${ }^{26}$ A full description of this process is provided in the SI. ${ }^{b}$ From single-crystal XRD data. ${ }^{c}$ From TOF powder ND data. ${ }^{7}{ }^{d}$ From synchrotron powder XRD data. ${ }^{5}$

cleaved again to an appropriate size and mounted on a glass fiber with paratone oil. The single-crystal XRD data were obtained under a flow of nitrogen at $100 \mathrm{~K}$ with a Bruker Kappa APEX 2 CCD diffractometer. The detector-to-sample distance was $50 \mathrm{~mm}$ with monochromated Mo $\mathrm{K} \alpha(\lambda=0.71073 \mathrm{~nm})$. For integration of the data, the SAINT-V7.23A program ${ }^{30}$ was used. An absorption (numerical, faceindexed) correction was applied to the data in the program XPREP, and structure solution was performed with XS in the Olex2 Suite. ${ }^{31,32}$

Absorbance Measurements. Optical measurements were gathered over the range $0.70-2.92 \mathrm{eV}(703-424 \mathrm{~nm})$ at $298 \mathrm{~K}$ using a Nikon Ti2000-U inverted microscope as reported previously. ${ }^{33-35}$ A slice of $\mathrm{Mn}_{3} \mathrm{Ta}_{2} \mathrm{O}_{8}$ was removed from the bulk single crystal with a diamond saw. This slice was then polished with silicon carbide media, ending with 1200 grit. The sample was sonicated in acetone to remove surface contamination. The slice had a final thickness of $0.31 \mathrm{~mm}$ and was placed on a glass coverslip at the focus of a $20 \times$ extra-long working distance objective. Transmitted light was spatially filtered in the collection path to selectively examine a circular region of diameter $10 \mu \mathrm{m}$ in the focal plane of the objective. Spectra were acquired for $7 \mu$ s and accumulated 200 times, and spectra were acquired at multiple locations to ensure reproducibility. Absorbance curves were calculated from transmittance measurements and normalized by the crystal thickness to obtain the absorption coefficient $\alpha$.

Orientation Determination. Following the absorbance measurements, the same slice was mounted on a steel cylinder with clay. A back-reflection Laue diffraction pattern was obtained at room temperature. The detector-to-sample distance was $3 \mathrm{~cm}$ with polychromatic radiation from a Mo target. For determination of the crystal orientation, the Cologne Laue indexation program ${ }^{36}$ was used.

Band-Structure Calculations. The electronic band structure of $\mathrm{Mn}_{3} \mathrm{Ta}_{2} \mathrm{O}_{8}$ was investigated using a first-principles density functional theory approach, as implemented in the Vienna ab initio simulation package (VASP). ${ }^{37,38}$ The PBE functional within the projector augmented-wave method was used. ${ }^{39-41}$ Brillouin-zone sampling was done with a $\Gamma$-centered Monkhorst pack with $k$-mesh $3 \times 3 \times 3$; a cutoff energy of $500 \mathrm{eV}$ was used. ${ }^{42}$ The internal atomic positions were optimized using the force and total energy minimization. To describe correctly the $\mathrm{d}^{5}$ states of $\mathrm{Mn}^{2+}$, the exchange correlation functional in the generalized gradient approximation (GGA) with an on-site Coulomb term $(\mathrm{GGA}+U)$ was employed. We used LDAUTYPE=2, 
Table 4. Anisotropic Thermal Displacement Parameters $\left(\AA^{2} \times 10^{3}\right)$, Defined by $2 \pi^{2}\left(h^{2} a^{* 2} U_{11}+\ldots+2 h k a b U_{12}\right)$, for $\mathrm{Mn}_{3} \mathrm{Ta}_{2} \mathrm{O}_{8}$ from Single-Crystal XRD Data

\begin{tabular}{|c|c|c|c|c|c|c|}
\hline atom & $U_{11}$ & $U_{22}$ & $U_{33}$ & $U_{12}$ & $U_{13}$ & $U_{23}$ \\
\hline Ta1 & $8.9(3)$ & $8.7(3)$ & $7.4(3)$ & $0.26(9)$ & $-0.11(10)$ & $0.25(9)$ \\
\hline Mn1 & 13.1(7) & $11.7(7)$ & $13.8(6)$ & $2.8(5)$ & $-5.2(5)$ & $-2.1(5)$ \\
\hline $\mathrm{Mn} 2$ & $12.3(8)$ & $12.3(8)$ & $9.7(13)$ & 0 & 0 & 0 \\
\hline Mn3 & $10.3(8)$ & $10.3(8)$ & $8.6(13)$ & 0 & 0 & 0 \\
\hline $\mathrm{O} 1$ & $8(2)$ & $15(3)$ & $9(3)$ & $1(2)$ & $1(2)$ & $0(2)$ \\
\hline $\mathrm{O} 2$ & 13(3) & $6(2)$ & 14(3) & $2(2)$ & $-2(2)$ & $-1(2)$ \\
\hline $\mathrm{O} 3$ & $7(3)$ & $11(3)$ & $14(3)$ & $2(2)$ & $1(2)$ & $-0.1(19)$ \\
\hline O4 & 7(2) & 14(3) & $8(3)$ & $0(2)$ & $-2(2)$ & $-3(2)$ \\
\hline
\end{tabular}

as implemented in VASP, with $U=2$ or $3 \mathrm{eV}$ for the Mn d states. ${ }^{24,43}$ In addition, the electronic-band-structure calculations with $U=0,1.5$, or $3 \mathrm{eV}$ for the Ta $\mathrm{d}$ states were performed to verify the nature of the conduction band. Finally, to study the optical properties of the oxide, the complex dielectric function, $\varepsilon(\omega)=\varepsilon_{1}(\omega)+i \varepsilon_{2}(\omega)$, was calculated based on the electronic band structure and polarization and momentum operators. ${ }^{44}$ The imaginary part, $\varepsilon_{2}(\omega)$, is related to the optical absorption at a given frequency $\omega$.

\section{RESULTS AND DISCUSSION}

Structure Comparison. The crystallographic and acquisition parameters of a single-crystal of $\mathrm{Mn}_{3} \mathrm{Ta}_{2} \mathrm{O}_{8}$ are provided in Table 1, with the previously reported structure solutions determined via powder neutron diffraction (ND) and synchrotron powder XRD., In the first report of the $\mathrm{Mn}_{3} \mathrm{Ta}_{2} \mathrm{O}_{8}$ structure, electron diffraction data suggested both a primitive space group and a larger $c$ axis (multiplied by 3 or 6). ${ }^{5}$ Neither of these were evident in the single-crystal structure solution. In precession images of the collected data (see the Supporting Information, SI), the structure solution reported herein accounts for all major reflections. There are some background-level reflections that could be a result of a superstructure, but primitive tetragonal lattices and/or larger $c$ axes produce inferior fitting of the major reflections.

The major difference between these structure solutions is the contraction of the single-crystal lattice parameters, and a experiences a greater change than $c$. This contraction can be attributed to the lower temperature at which the single-crystal data were collected. A second consequence of this contraction is a reduction in the interatomic distances of the single-crystal sample, provided in Table 2 . The atomic positions, provided in Table 3, are very similar. Anisotropic thermal displacement parameters for the single-crystal structure are provided in Table 4.

The anion-deficient, fluorite-related $\mathrm{Mn}_{3} \mathrm{Ta}_{2} \mathrm{O}_{8}$ structure's cation topology is an approximate cubic-close-packed cation lattice (the distorted, face-centered-cubic motif is shown in Figure 3) and maintains four distinct cation coordination environments: four-coordinate $(\mathrm{Mn} 3)$, six-coordinate $(\mathrm{Ta})$, seven-coordinate $(\mathrm{Mn} 1)$, and eight-coordinate (Mn2). Each coordination polyhedron can be compared to the ideal cube of fluorite if the cube is distorted and missing anions. ${ }^{7}$ This results in a complex cation network, as shown in Figure 4, which has two compositionally unique layers on unusual angles with inversion operations that produce the $\mathrm{ABC}$ motif of the cubicclose-packed system. The odd angles arise from the tetragonal cell because the close-packed layers in fluorite can be viewed in the $\left[\begin{array}{lll}1 & 0 & 1\end{array}\right]$ direction, which is the face diagonal of the cubic cell. With a tetragonal cell, however, the same diagonal becomes distorted, making layer designation difficult. This complexity, however, can be simplified by extracting a

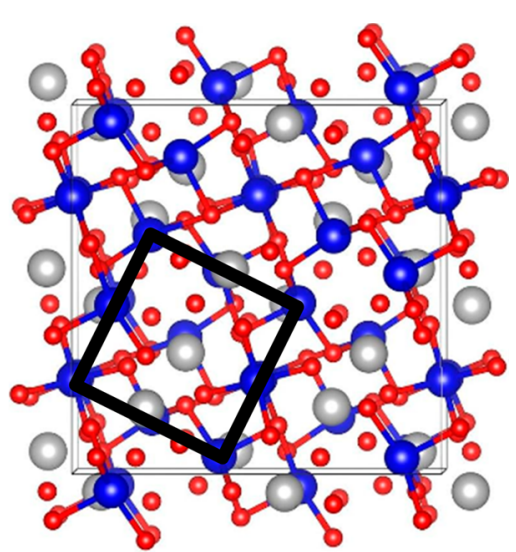

Figure 3. Unit cell of $\mathrm{Mn}_{3} \mathrm{Ta}_{2} \mathrm{O}_{8}$ viewed along the $c$ axis showing the slightly distorted face-centered-cubic lattice (black square) adopted by the $\mathrm{Mn}$ (blue) and Ta (gray) atoms.

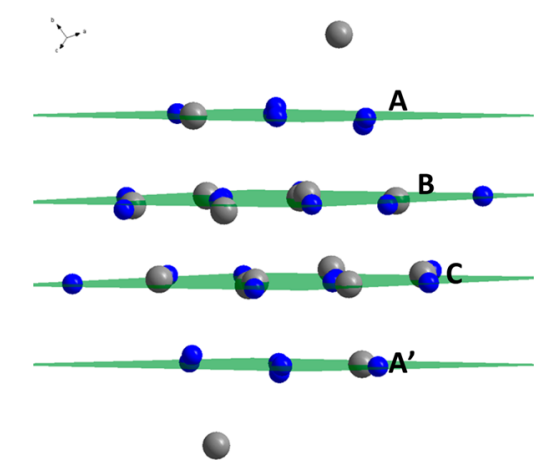

Figure 4. Unit cell of $\mathrm{Mn}_{3} \mathrm{Ta}_{2} \mathrm{O}_{8}$ (blue $=\mathrm{Mn}$ and gray $=\mathrm{Ta}$; the $\mathrm{O}$ atom has been omitted for clarity) in the [70 4067$]$ direction, which is close to a face diagonal. The cubic-close-packed layers (green planes) are in the form $A B C$, where $B$ and $C$ are compositionally the same layer but with an inversion operation. The same is true for A and $\mathrm{A}^{\prime}$, but the overall cation position is preserved. Because the unit cell is on an angle, additional layers will be combinations of these four.

single close-packed layer, as given in Figure $5{ }^{45}$ Inside each layer, there is a repeating rectangular unit of 20 atoms $(12 \mathrm{Mn}$ and $8 \mathrm{Ta}$ ) that can be used to generate the entire cation occupancy. Each adjoining unit, in all directions, is translated by a single row of atoms. Furthermore, all of the close-packed layers in $\mathrm{Mn}_{3} \mathrm{Ta}_{2} \mathrm{O}_{8}$ share this repeating unit; that is, the layers are identical. The differences in the unit cell layers are the result of shifts and inversions, but this overarching pattern is maintained in each layer.

Optical Band Gap. The optical band gap of $\mathrm{Mn}_{3} \mathrm{Ta}_{2} \mathrm{O}_{8}$ was characterized through analysis of the fundamental absorption 


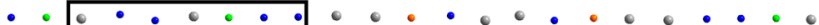

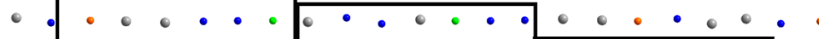

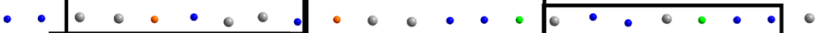

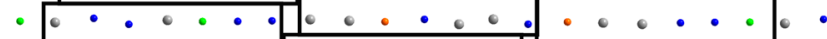

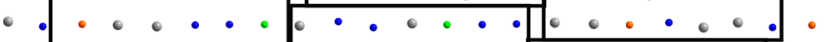

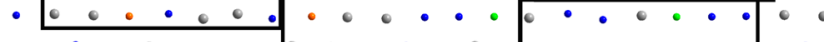

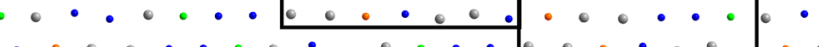

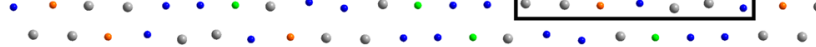

Figure 5. Close-packed layer of $\mathrm{Mn}_{3} \mathrm{Ta}_{2} \mathrm{O}_{8}$ where blue $=\mathrm{Mn} 1$, green = $\mathrm{Mn} 2$, orange $=\mathrm{Mn} 3$, and gray $=\mathrm{Ta} 1$ (the $\mathrm{O}$ atoms have been omitted for clarity). The repeating unit is a 20 -atom rectangle as shown, which is translated to one atomic row and column to form a steplike pattern. The deviations from a perfect 2D plane can be viewed in Figure 4.

edge in collected absorbance spectra. The band gap was approximated as the intersection between a linear extrapolation of the band edge and the background in the plot of the absorption coefficient, $\alpha$, versus incident photon energy, $h \nu$, as depicted in Figure 6. This method does not assume that the band gap is direct or indirect and yields a transition energy of $1.89 \mathrm{eV}$, which is consistent with the reddish brown color of the crystal. Absorbance spectra collected at other locations on the crystal confirm this result. Results from Laue diffraction show that the [001] crystal axis was oriented roughly collinear with the illumination direction. For reference, the plots and band gaps obtained with $\alpha^{2}$ and $\alpha^{1 / 2}$ versus $h \nu$ are provided in the SI (with transition energies of 1.97 and $1.83 \mathrm{eV}$, respectively). As this is a crystalline material, all of the plots are in terms of $\alpha$ versus $h \nu$, rather than the $\alpha h \nu$ versus $h \nu$ that is favored by the Tauc equation, which had been developed for amorphous materials. ${ }^{46}$ The goodness-of-fit of linear models of the band edge in the plots of $\alpha^{1 / 2}$ or $\alpha^{2}$, which would represent an indirect or direct band gap, respectively, are comparable. Although the electronic band structure in Figure 7 does show an indirect band gap, the energy difference between the direct and indirect gaps is minute. As the nature of the optical band gap is unclear, we instead report an approximate transition energy derived from the absorption coefficient spectrum.

Electronic Band Structure. According to the previously reported magnetic characterization of $\mathrm{Mn}_{3} \mathrm{Ta}_{2} \mathrm{O}_{8}$, it has a complex antiferromagnetic (AFM) structure, which is assigned to a strong exchange coupling along the helical strings of $\mathrm{Mn} 1$ atoms connected via short bonds with $\mathrm{O} 3$ atoms (cf. Table 2). ${ }^{7}$

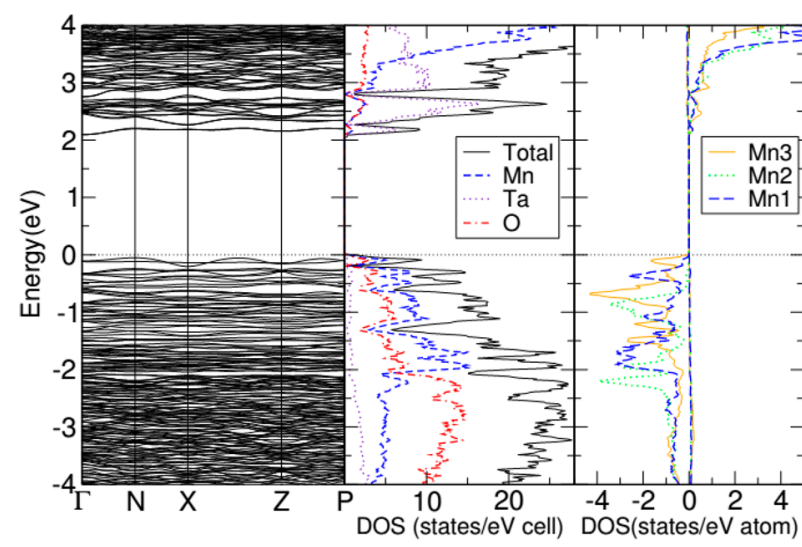

Figure 7. Electronic band structure of $\mathrm{AFM} \mathrm{Mn}_{3} \mathrm{Ta}_{2} \mathrm{O}_{8}$ as obtained from GGA $+U$ calculations with $U=2 \mathrm{eV}$ for the Mn d states (left) and the corresponding total (middle) and partial (right) DOS. The partial DOS is spin-resolved. The Fermi level is at $0 \mathrm{eV}$.

This agrees with our spin-polarized GGA $+U$ calculations, which show that the total energy of the AFM configuration is $0.344 \mathrm{eV}$ lower than the total energy of the ferromagnetic (FM) state. The calculated magnetic moments on $\mathrm{Mn}$ atoms are 4.54, 4.58 , and $4.44 \mu_{\mathrm{B}}$ in the $\mathrm{FM}$ configuration and $\pm 4.52, \pm 4.57$, and $\pm 4.42 \mu_{\mathrm{B}}$ in the AFM configuration for Mn1, Mn2, and $\mathrm{Mn} 3$, respectively. These values are in accordance with the reported magnetic moment of $4.0 \mu_{\mathrm{B}}{ }^{7}$ The calculated band gaps, $1.7 \mathrm{eV}$ for the FM case and $2.1 \mathrm{eV}$ for the AFM case, are nearly equally close to the experimentally determined value of $1.89 \mathrm{eV}$.

The electronic band structure of AFM $\mathrm{Mn}_{3} \mathrm{Ta}_{2} \mathrm{O}_{8}$ calculated within GGA+U with $U=2 \mathrm{eV}$ for the $\mathrm{Mn} \mathrm{d}$ states is shown in Figure 7. Both the top of the valence band and the bottom of the conduction band show low-energy dispersion for the bands calculated along the high-symmetry directions of the Brillouin zone. The bottom of the conduction band consists of a single band that is split from the rest of the bands. From the total and projected density of states (DOS), the valence band consists of the hybridized $\mathrm{Mn} \mathrm{d}-\mathrm{O} \mathrm{p}$ states, whereas the Ta s (the single band at the bottom) and d states are the major contributors to the conduction band bottom. The structure of $\mathrm{Mn}_{3} \mathrm{Ta}_{2} \mathrm{O}_{8}$ contains three crystallographically nonequivalent types of $\mathrm{Mn}$ atoms, Mn1, Mn2, and Mn3, which are seven-, eight-, and
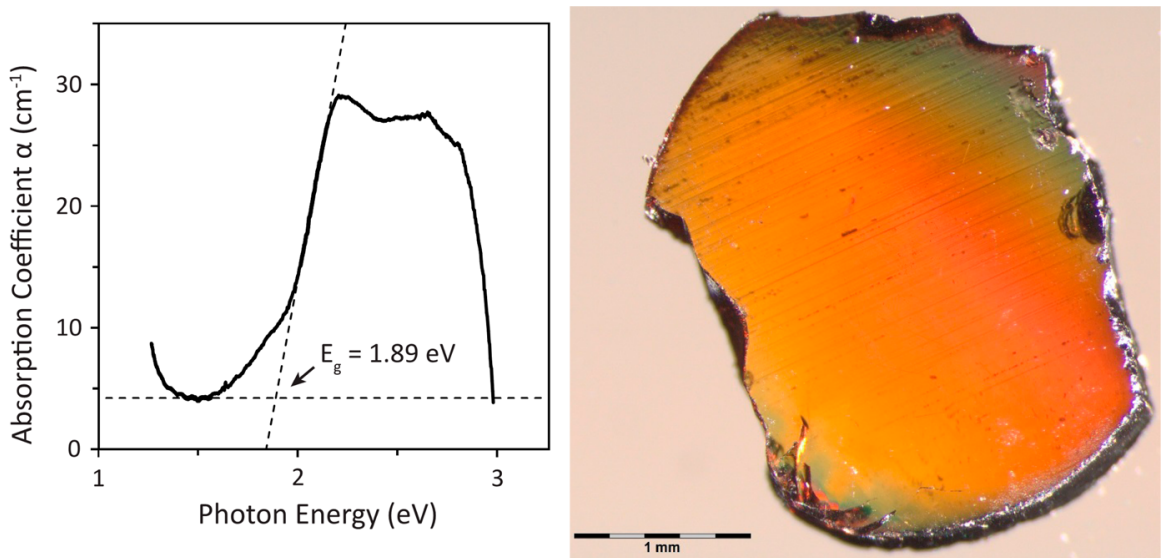

Figure 6. Plot of the thickness-normalized absorption coefficient, $\alpha$, versus photon energy (left) of a 0.31-mm-thick slice of $\mathrm{Mn}_{3} \mathrm{Ta}_{2} \mathrm{O}_{8}$ (right). The band edge and background are linearly extrapolated to yield a close approximation of the band gap. The $1.89 \mathrm{eV}$ band gap corresponds well with the reddish-brown color of the crystal. Perimeter imperfections in the crystal were caused by the polishing process. 
four-coordinate with $\mathrm{O}$ atoms, respectively (cf. Table 2 ). The projected DOS (cf. Figure 7) reveals that only the states of $\mathrm{Mn} 1$ and Mn3 contribute near the top of the valence band. Therefore, the Mn1 and Mn3 states are expected to control the electronic transitions across the band gap.

To verify the nature of the conduction band, additional calculations with $U=0,1.5$, and $3 \mathrm{eV}$ for the Ta d states were performed. Apart from the slight increase of the band gap by $0.3 \mathrm{eV}$ as the on-site Coulomb value increased from 0 to $3 \mathrm{eV}$, the unoccupied $\mathrm{Ta} \mathrm{d}$ states governed the bottom of the conduction band independent of the $U$ value. Similarly, an increased value of Coulomb $U$ for the $\mathrm{Mn} \mathrm{d}$ states, namely, from 2 to $3 \mathrm{eV}$, resulted in a larger band-gap value of $2.4 \mathrm{eV}$ in the AFM case, whereas the nature of the valence and conduction bands remained unchanged. We note here that the peculiar electronic band structure of $\mathrm{Mn}_{3} \mathrm{Ta}_{2} \mathrm{O}_{8}$ with $\mathrm{Mn}$ or Ta states governing the valence or conduction bands, respectively, suggests a possibility for controlled carrier generation via targeted substitutional doping, as has been performed for other $\mathrm{Mn}^{2+}$ materials. $^{25}$

Finally, the real and imaginary parts of the dielectric constant were calculated to understand the optical properties of $\mathrm{Mn}_{3} \mathrm{Ta}_{2} \mathrm{O}_{8}$. The results, given in Figure 8, verify the onset of

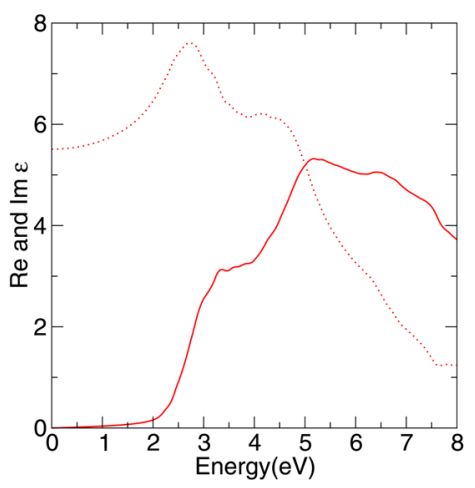

Figure 8. Calculated imaginary (solid line) and real (dotted line) parts of the complex dielectric function for $\mathrm{Mn}_{3} \mathrm{Ta}_{2} \mathrm{O}_{8}$.

the electronic transitions across the band gap that was determined experimentally. The imaginary part of the calculated complex dielectric function is related to the optical absorption at a given frequency $\omega$ and compares favorably with the spectroscopically measured $\alpha(\omega)$ (cf. Figure 6).

\section{CONCLUSION}

$\mathrm{Mn}_{3} \mathrm{Ta}_{2} \mathrm{O}_{8}$, a specific composition in the complex $\mathrm{Mn}-\mathrm{Ta}-\mathrm{O}$ system, was targeted for crystal growth, and large crystals were successfully obtained via the optical floating-zone method. The crystal structure of this material agrees well with prior powder diffraction studies, with a slight lattice contraction as a result of differing collection temperatures. This structure is an example of a rare fluorite-related tetragonal phase that contains four different cation coordination environments and a complex cation topology with repeating units of 20 cations. Absorbance spectroscopy determined the approximate band gap as $1.89 \mathrm{eV}$, which agrees with the calculated electronic band structure and optical properties. The validity of the electronic structure is corroborated by its agreement with the previously reported magnetic characterization of $\mathrm{Mn}_{3} \mathrm{Ta}_{2} \mathrm{O}_{8}$. The electronic structure also shows that the absorption edge is governed by the four- and seven-coordinate $\mathrm{Mn}$ sites.

\section{ASSOCIATED CONTENT}

\section{Supporting Information}

X-ray crystallographic data in CIF format, coordinate transformations, precession X-ray images, orientation determination, alternative band-gap calculations, AFM configuration, and GGA (no $U$ ) DOS plots. The Supporting Information is available free of charge on the ACS Publications website at DOI: 10.1021/ acs.inorgchem.5b00853.

\section{AUTHOR INFORMATION}

\section{Corresponding Author}

*E-mail: krp@northwestern.edu.

\section{Present Address}

"M.O.: Department of Physics, University of California, Irvine, CA 92697.

\section{Author Contributions}

The manuscript was written through contributions of all authors. All authors have given approval to the final version of the manuscript.

Notes

The authors declare no competing financial interest.

\section{ACKNOWLEDGMENTS}

K.R. and E.A.P. acknowledge that this material is based upon work supported by the National Science Foundation Graduate Research Fellowship Program under Grant DGE-1324585. K.R. and K.R.P. gratefully acknowledge additional support from the Department of Energy Basic Energy Sciences Award DE-FG0208ER46536. E.A.P. and R.P.V.D. acknowledge the National Science Foundation Grant CHE-1152547. R.K., J.E.M., and M.C.H. acknowledge support from the National Science Foundation Materials Research Science and Engineering Center (Grant DMR-1121262). M.O. and G.T. used in this research resources of the National Energy Research Scientific Computing Center (NERSC), a DOE Office of Science User Facility supported by the Office of Science of the U.S. Department of Energy under Contract No. DE-AC0205CH11231. Single-crystal X-ray measurements were performed at IMSERC at Northwestern University (NU), which is supported with grants from NSF-NSEC, NSF-MRSEC, the Keck Foundation, the State of Illinois, and NU. This work made use of the OMM Facility and the J. B. Cohen X-ray Diffraction Facility, both of which are supported by the MRSEC program of the National Science Foundation (Grant DMR-1121262) at the Materials Research Center of NU. The authors thank Charlotte Stern and Amy Sarjeant (both at NU) for helpful discussions regarding the crystal structure.

\section{REFERENCES}

(1) Smit, J. P.; Stair, P. C.; Poeppelmeier, K. R. Chem.-Eur. J. 2006, 12, 5944-5953.

(2) Hong, H. Y. P.; Dwight, K. Mater. Res. Bull. 1974, 9, 775-780.

(3) Pan, J.; Yau, L. Z.; Chen, L. G.; Zhao, G. W.; Zhou, G. E.; Guo, C. X. J. Lumin. 1988, 40-1, 856-857.

(4) Edwards, D. D.; Mason, T. O.; Goutenoire, F.; Poeppelmeier, K. R. Appl. Phys. Lett. 1997, 70, 1706-1708.

(5) Esmaeilzadeh, S.; Grins, J.; Fitch, A. J. Mater. Chem. 1998, 8, 2493-2497.

(6) Edwards, D. D.; Mason, T. O.; Sinkler, W.; Marks, L. D.; Goutenoire, F.; Poeppelmeier, K. R. J. Solid State Chem. 1998, 140, $242-250$.

(7) Grins, J.; Esmaeilzadeh, S.; Berastegui, P.; Eriksson, S. J. Mater. Chem. 1999, 9, 1575-1578. 
(8) Dolgonos, A.; Lam, K.; Poeppelmeier, K. R.; Freeman, A. J.; Mason, T. O. J. Appl. Phys. 2014, 115, 013703.

(9) Schonberg, N. Acta Metall. 1955, 3, 14-16.

(10) Bertaut, E. F.; Corliss, L.; Forrat, F.; Aleonard, R.; Pauthenet, R. J. Phys. Chem. Solids 1961, 21, 234-251.

(11) Turnock, A. C. J. Am. Ceram. Soc. 1966, 49, 382-384.

(12) Grins, J.; Tyutyunnik, A. J. Solid State Chem. 1998, 137, 276282.

(13) Esmaeilzadeh, S.; Grins, J.; Larsson, A. K. J. Solid State Chem. 1999, 145, 37-49.

(14) Esmaeilzadeh, S.; Lidin, S.; Nygren, M.; Grins, J. Z. Anorg. Allg. Chem. 2000, 626, 148-159.

(15) Grins, J.; Esmaeilzadeh, S.; Andersson, M.; Morawski, A. J. Mater. Chem. 2000, 10, 2197-2200.

(16) Esmaeilzadeh, S.; Grins, J. Solid State Sci. 2002, 4, 117-123.

(17) Tarakina, N. V.; Tyutyunnik, A. P.; D’Yachkova, T. V.; Zubkov, V. G.; Zainulin, Y. G.; Sayagues, M. J.; Svensson, G. J. Struct. Chem. 2003, 44, 252-255.

(18) Tarakina, N. V.; Tyutyunnik, A. P.; Zubkov, V. G.; D’Yachkova, T. V.; Zainulin, Y. G.; Hannerz, H.; Svensson, G. Solid State Sci. 2003, 5, 983-994.

(19) Jehn, H.; Olzi, E. J. Less-Common Met. 1972, 27, 297-309.

(20) Kuo, K. Acta Metall. 1953, 1, 720-724.

(21) Wang, M. S.; Sundman, B. Metall. Trans. B 1992, 23, 821-831.

(22) Irmscher, K.; Naumann, M.; Pietsch, M.; Galazka, Z.; Uecker, R.; Schulz, T.; Schewski, R.; Albrecht, M.; Fornari, R. Phys. Status Solidi A 2014, 211, 54-58.

(23) Ingram, B. J.; Gonzalez, G. B.; Kammler, D. R.; Bertoni, M. I.; Mason, T. O. J. Electroceram. 2004, 13, 167-175.

(24) Peng, H. W.; Lany, S. Phys. Rev. B 2012, 85, 201202.

(25) Peng, H.; Zakutayev, A.; Lany, S.; Paudel, T. R.; d'Avezac, M.; Ndione, P. F.; Perkins, J. D.; Ginley, D. S.; Nagaraja, A. R.; Perry, N. H.; Mason, T. O.; Zunger, A. Adv. Funct. Mater. 2013, 23, 5267-5276.

(26) Hautier, G.; Miglio, A.; Waroquiers, D.; Rignanese, G.-M.; Gonze, X. Chem. Mater. 2014, 26, 5447-5458.

(27) Im, J.; Trimarchi, G.; Peng, H.; Freeman, A. J.; Cloet, V.; Raw, A.; Poeppelmeier, K. R. J. Chem. Phys. 2013, 138, 194703.

(28) Cloet, V.; Raw, A.; Poeppelmeier, K. R.; Trimarchi, G.; Peng, H.; Im, J.; Freeman, A. J.; Perry, N. H.; Mason, T. O.; Zakutayev, A.; Ndione, P. F.; Ginley, D. S.; Perkins, J. D. Chem. Mater. 2012, 24, 3346-3354.

(29) Trimarchi, G.; Peng, H.; Im, J.; Freeman, A. J.; Cloet, V.; Raw, A.; Poeppelmeier, K. R.; Biswas, K.; Lany, S.; Zunger, A. Phys. Rev. B 2011, 84, 165116 .

(30) APEX v2.1-0, 7.23A ed.; Bruker AXS Institute: Madison, WI, 2005.

(31) Sheldrick, G. M. Acta Crystallogr., Sect. A: Found. Crystallogr. 2008, 64, 112-122.

(32) Dolomanov, O. V.; Bourhis, L. J.; Gildea, R. J.; Howard, J. A. K.; Puschmann, H. J. Appl. Crystallogr. 2009, 42, 339-341.

(33) Mesbah, A.; Lebègue, S.; Klingsporn, J. M.; Stojko, W.; Van Duyne, R. P.; Ibers, J. A. J. Solid State Chem. 2013, 200, 349-353.

(34) Koscielski, L. A.; Pozzi, E. A.; Van Duyne, R. P.; Ibers, J. A. J. Solid State Chem. 2013, 205, 1-4.

(35) Ward, M. D.; Pozzi, E. A.; Van Duyne, R. P.; Ibers, J. A. J. Solid

State Chem. 2014, 212, 191-196.

(36) Schumann, O. J. Cologne Laue indexation program, 4.0 ed.; Cologne Laue: Cologne, Germany, 2008.

(37) Kresse, G.; Furthmuller, J. Phys. Rev. B 1996, 54, 11169-11186.

(38) Kresse, G.; Furthmuller, J. Comput. Mater. Sci. 1996, 6, 15-50.

(39) Blochl, P. E. Phys. Rev. B 1994, 50, 17953-17979.

(40) Kresse, G.; Joubert, D. Phys. Rev. B 1999, 59, 1758-1775.

(41) Perdew, J. P.; Burke, K.; Ernzerhof, M. Phys. Rev. Lett. 1996, 77, 3865-3868.

(42) Monkhorst, H. J.; Pack, J. D. Phys. Rev. B 1976, 13, 5188-5192.

(43) Dudarev, S. L.; Botton, G. A.; Savrasov, S. Y.; Humphreys, C. J.; Sutton, A. P. Phys. Rev. B 1998, 57, 1505-1509.

(44) Dressel, M.; Grüner, G. Electrodynamics of Solids; Cambridge University Press: Cambridge, U.K., 2002.
(45) Anderson, M. T.; Vaughey, J. T.; Poeppelmeier, K. R. Chem. Mater. 1993, 5, 151-165.

(46) Tauc, J.; Grigorov, R.; Vancu, A. Phys. Status Solidi 1966, 15, 627-637. 